\title{
Helicobacter Pylori Infections, Gastrointestinal Diseases, Diagnostic Implications and Treatment Protocols: Recent Developments
}

\author{
Abu SM Giasuddin ${ }^{1}$, Khadija A Jhuma ${ }^{1}$, Wadud A Khan ${ }^{2}$ and Tawfiq Aziz ${ }^{3}$ \\ ${ }^{1}$ Professor of Biochemistry \& Immunology (Retd.), Department of Laboratory Medicine, Bangladesh \\ ${ }^{2}$ Senior Consultant in Internal Medicine (Gastroenterology), Impulse Hospital, Bangladesh \\ ${ }^{3}$ Assistant Professor \& Consultant in Internal Medicine (Gastroenterology), Medical College for Women \& Hospital, Bangladesh
}

Submission: October 10, 2019; Published: November 12, 2019

*Corresponding author: Abu SM Giasuddin, Professor of Biochemistry \& Immunology (Retd.), Senior Consultant (Biochemistry \& Immunology, Department of Laboratory Medicine, Impulse Hospital, ImHS \& RC Ltd, 304/E Tejgaon Industrial Area, Dhaka-1208, Bangladesh

\begin{abstract}
Helicobacter pylori (H. pylori) is a common infection with $50 \%$ of the world population being involved approximately. Once infected, it will often persist with evidence showing strong correlation between its presence and gastrointestinal diseases such as gastritis, peptic ulcer disease, gastric carcinoma and mucosa-associated lymphoid tissue (MALT) lymphoma. A number of techniques, broadly grouped into invasive and non-invasive methods, have been developed to diagnose H. pylori infection. The efficiency of these methods in confirming or rejecting provisional/clinical diagnosis as well as the costs of these tests are the two main factors in the choice of diagnostic method used in hospital laboratories. Invasive testing methods are not feasible options for routine testing in laboratories and therefore, non-invasive alternatives should be used preferably. However, with the increase in antimicrobial resistance, it was becoming more important to conduct further testing including polymerase chain reaction (PCR) method to provide clinicians with the resistance/susceptibility profile required to make effective treatments possible. The present article provides an overview of recent developments in reference to laboratory diagnostic and treatment protocols of $H$. pylori infection, responsible for a wide spectrum of upper gastrointestinal diseases.
\end{abstract}

Keywords: Helicobacter pylori; H pylori infection; Gastrointestinal diseases; Diagnosis; Treatment

Abbreviations: CLOs: Campylobacter-Like Organisms; MALT: Mucosa-Associated Lymphoid Tissue; PCR: Polymerase Chain Reaction; IFN: Interferon; RUT: Rapid Urease Test; UBT: Urea Breath Test; HE: Haematoxylin and Eosin; ELISA: Enzyme - Linked Immunosorbent Assay; PPI: Proton Pump Inhibiters; NICE: National Institute for Health and Care Excellence

\section{Historical Background}

Helicobacter pylori (H. pylori) is a small, spiral-shaped, highly motile Gram-negative bacterium related to Campylobacter which colonizes the non-acid-secreting mucosa of the stomach and upper intestinal tract. Infection with H. pylori is very common, with $50 \%$ of the world's population infected approximately. Once present, infection will often persist, with evidence showing strong correlation between its presence and a wide spectrum of supper gastrointestinal diseases such as gastritis, peptic ulcer disease, gastric carcinoma and mucosa-associated lymphoid tissue (MALT) lymphoma. Originally called Campylobacter pyloridis and then corrected to Campylobacter pylori, it was renamed again due to taxonomic data as Helicobacter Pylori in a new genus, Helicobacter. H. pylori was discovered by Marshall \& Warren [1-3] at the time when was commonly thought that stress and diet were the only causes of peptic ulcer. In 1985, Marshall performed self-inoculation by Campylobacter-like organisms (CLOs) and exhibited self-inoculated gastritis. Subsequently, he treated it successfully with metronidazole and bismuth salts, thereby proving their ability to cause gastritis. In 2005, for their work on H. pylori in the understanding of gastric disease, Marshall \& Warren [4] were awarded the Nobel Prize in Physiology or Medicine.

\section{Pathological Aspects}

While most cases of infection are asymptomatic, long-term carriage significantly increase the risk of developing disease. Studies have reported that approximately 10\% develop peptic 
ulcer disease, 1-3\% develop gastric adenocarcinoma and $<0.1 \%$ develop MALT lymphoma [5]. The pathogenicity of H. pylori and subsequent risk of cancer is dependent on the bacterial and host genotypes as well as environmental exposures [6]. Two loci play a part in determining the virulence of $H$. pylori: the cag pathogenicity island (cag PAI) and VacA. The cag PAI encodes the CagA protein, often used to differentiate between strains resulting in increased cellular migration and a link to oncogenesis. As well as encoding for CagA, cag PAI also delivers H. pylori peptidoglycan tohost cells, triggering an intracellular signaling cascade. This culminates in the production of type I interferon (lFN), an important group of proteins involved in regulation of the immune system. The toxin VacA, encoded by the VacA locus, also has a role to play in modulation of the immune system and inflammatory response [7].

It has been postulated that there is a synergistic relationship between high salt diets and H-pylori infection on gastric inflammation and damage. The link has been studied in gerbils, although the mechanisms of action are not fully understood [8]. Some hypotheses point to a link between salt and its effect on gastric mucosa and epithelium, allowing carcinogens to pass into gastric tissue and thus facilitate malignant transformation. Other studies linked salt to increased inflammation and upregulation of cytokines such as interferon. A more recent study showed a potential correlation between high gastric salt concentration and modulation of gene expression in H. pylori [9].

\section{Methods of Laboratory Diagnosis}

The techniques developed to diagnose H. pylori infection can be grouped broadly into invasive and noninvasive methods. Invasive methods include Culture and histopathology are included in invasive methods. These require accessing the stomach lining for biopsy, either by endoscopy or an alternative such as nasogastric tube or orogastric brush. The endoscopic features of $H$. pylori infection are non-specific and difficult to detect using standard methods; However, improvements in imaging and microscopy have led to better detection and subsequently better biopsy samples [10].

On a gastric mucosa biopsy, several tests can be performed: rapid urease test (RUT), histopathology, smear (cytopathology), culture and polymerase chain reaction (PCR) methods. The RUT is similar in principle to the urea breath test (UBT). It requires a sample of gastric mucosa or mucus, which is brought into contact with urea, resulting in the detection of hydrolysis products. The initial test used phenol red, which changes from yellow to pink or red as the $\mathrm{pH}$ increases due to $\mathrm{CO}_{2}$, production. This method was evaluated in detail in 1989 by McNulty et al who found it to be a cheap and rapid alternative to the staining or culture of biopsy samples $[11,12]$.

Staining methods are available for the histological investigation of biopsy samples for $H$. pylori with the most common being a routine haematoxylin and eosin (HE) stain. In the UK microscopy is carried out using carbol fuchsin or Sandiford's stain. Staining and examination of the preparation using Gram or Giemsa stains need only be performed if the culture result is negative and biopsy urease test positive [13].

H. Pylori culture can be performed on selective agars which contain specific antibiotics to inhibit commensal bacteria and on non-selective agars. Culture must be performed as soon as possible after sampling and incubated under micro-aerobic conditions $\left(85 \% \mathrm{~N}_{2}, 10 \% \mathrm{CO}_{2}, 5 \% \mathrm{O}_{2}\right)$ at $35-37^{\circ} \mathrm{C}$ for at least seven days before discarding as negative [14]. The application of PCR methods to gastric biopsy samples for the identification of $H$. pylori was first described by Hammar et al. [15] first described the application of PCR methods to gastric biopsy samples for the identification of $H$. pylori. The assay targeted A DNA region coding for a species-specific protein antigen present in all strains of $H$. pylori was targeted in the assay. Subsequently, availability of methods for extracting bacterial DNA from faecal samples at overall decreasing cost and availability and ease of use of molecular methods, has improved PCR testing. However, there is a risk that past infection will be identified, leading to false-positive results [16]. On the other hand, an advantage of PCR is the ability to identify genes relating to antimicrobial resistance mechanisms.

Non-invasive methods include Serological testing, antigen testing from faecal samples and the UBT are the non-invasive methods developed over time. Blood serology is understood to be the least accurate method as it detects antibody to Helicobacter and does not differentiate active from past infection. A review conducted by Leheji et al. [17] showed that kits detecting IgA, IgG and IgM simultaneously or IgA alone do not perform well as those that detect only IgG antibodies. Data comparing the performance of the UBT and the stool antigen test are summarized [18].

Antigen testing can be performed by enzyme -Linked immunosorbent assay (ELISA) or rapid lateral-flow methods. The stool antigen test allows collection of the sample at home and is usually recommended when UBT is not available. Both methods use antibodies against $H$. pylori antigen to detect the presence of the bacteria, but performance of commercial kits has been shown to be uneven [19]. The cost of these tests is a factor in the choice of diagnostic method used in the laboratory. The UBT is the most expensive, followed by stool antigen and finally blood serology. A Limitation of UBT and stool antigen test is the need to cease treatment: with proton pump inhibiters (PPI; within two weeks of testing) and antibiotics (within four weeks of testing), as these drugs suppress bacteria and may lead to false-negative results [20].

\section{Treatment Protocols}

As stated in the guidelines of National Institute for Health and Care Excellence (NICE) UK, the first-line treatment of H. pylori include a seven-day, twice-daily course of treatment with a PPI plus two antibiotics i.e. amoxicillin and either clarithromycin or metronidazole. second-line treatment with a PPI plus amoxicillin and either clarithromycin or metronidazole are given to patients still 
having symptoms after seven days. This triple therapy has been the standard treatment for $H$. pylori infection for the past 15 years. However, there has been an increase in antimicrobial resistance which is causing concern over the efficacy of this treatment. Recent treatment options for clarithromycin-resistant $H$. pylori were suggested as to return to the initial treatment using bismuth in the form of bismuth subcitrate. Its mechanisms of action are not fully understood but it has been shown to have anti-inflammatory and bactericidal action [21,22].

Initially, testing for clarithromycin resistance has been recommended to determine if traditional triple treatment is effective. If the strain causing infection is found to be resistant, then metronidazole administration is recommended. However, resistance rates to metronidazole have also been increasing. A regimen containing levofloxacin is an effective alternative but should be used wisely to avoid development of drug resistance. It has also been suggested that a bismuth-based quadruple therapy comprising a PPI plus a standardized three-in-one capsule containing bismuth subcitrate potassium, metronidazole and tetracycline (BMT available under Iicence as Pylera) be used [22].

PCR is a useful tool for identification of H. pylori and this is becoming all the more apparent with the increase in drug-resistant strains. This method offers detection of the clarithromycin-resistance gene from fecal samples, gastric juice or biopsy material, which is a clinically useful tool for determining patient treatment. Traditional antibiotic susceptibility testing methods using disc diffusion or broth micro-dilution may also be used to identify susceptibility/resistance to various antibiotics [23].

\section{Conclusions}

Non-invasive alternatives should be used as invasive testing methods are not easy options for routine testing in laboratories. Blood serology testing, although a cheaper option, does not lead to long-term savings with regard to patient care and treatment options, due to its poor performance efficiency. The UBT is expensive and not beneficial with regard to sensitivity and specificity. This effects on the long-term cost savings in patient care. Stool antigen testing seems to combine performance and cost-effectiveness. With increase in antimicrobial resistance, it is becoming more important to conduct further advanced tests such as PCR testing with increase in antimicrobial resistance. The clinicians must be provided with the resistance/susceptibility profiles by molecular biology (PCR) tests to make effective and efficient treatment decisions.

\section{References}

1. Brown LM (2000) Helicobacter pylori: Epidemiology and routes of transmission. Epidemiol Rev 22 (2): 283-297.

2. Dunn BE, Phadnis SH (1998) Structure, function and localization of Helicobacter pylori urease. Yale J Biol Med 71(2): 63-73.

3. Wanen JR, Marshall BJ (1983) Unidentified curved bacilli on gastric epithelium in active chronic gastritis. Lancet 1(8336): 1273-1275.
4. Marshall BJ, Armstrong JA, McGechie DB, Glancy RJ (1985) Attempt to fulfil Koch's postulates for pyloric Campylobacter. Med J Aust 142(8): 436-439.

5. Peek RM Jr, Crabtree JE (2006) Helicobacter infection and gastric neoplasia. J Pathol 208(2): 233-248.

6. Wroblewski LE, Peek RM Jr, Wilson KT (2010) Helicobacter pylori and gastric cancer: factors that modulate disease risk. Clin Microbiol Rev 23(4): 713-739.

7. Watanabe T, Asano N, Fichtner-Feigl S, Gorelick PL, Tsuji Y, et al. (2010) NOD1 contributes to mouse host defense against Helicobacter pylori via induction of type I IFN and activation of the ISGF3 signaling pathway. J Clin Invest 120(5): 1645-1662.

8. Gaddy JA, Radin JN, Loh JT, Zhang F, Washington MK, et al. (2013) High dietary salt intake exacerbates Helicobacter pylori-induced gastric carcinogenesis. Infect lmmun 81(6): 2258-2267.

9. Gancz H, Jones KR, Merrell DS (2008) Sodium chloride affects Helicobacter pylori growth and gene expression. J Bacteriol 190(11): 4100-4105.

10. Megraud F, Lehours P (2007) Helicobacter pylori detection and antimicrobial susceptibility testing. Clin Microbiol Rev 20(2): 280-322.

11. Uotani T, Graham DY (2015) Diagnosis of Helicobacter pylori using the rapid urease test. Ann Transl Med 3(1): 9.

12. McNulty, Dent JC, Uff JS, Gear MW, Wilkinson SP, et al. (1989) Detection of Campylobacter pylori by the biopsy urease test: an assessment in 1445 patients. Gut 30(8): 1058-1062.

13. Public Health England (2014) Investigation of gastric biopsies for Helicobacter pylori. UK Standards for Microbiology Investigations. PHE, London

14. Garza-Gonzalez E, Perez-Perez GI, Maldonado-Garza HI, BosquesPadilla FJ (2014) A review of Helicobacter pylori diagnosis, treatment and methods to detect eradication. World J Gastroenterol 20(6): 14381449.

15. Hammar M, Tyszkiewicz T, Wadstrom T, O Toole PW (1992) Rapid detection of Helicobacter pylori in gastric biopsy material by polymerase chain reaction. J Clin Microbiol 30(1): 54-58.

16. Hirschl AM, Makristathis A (2007) Methods to detect Helicobacter pylori: from culture to molecular biology. Helicobacter 12(Suppl 2): 6-11.

17. Laheij RJ, Straatman H, Jansen JB, Verbeek AL (1998) Evaluation of commercially available Helicobacter pylori serology kits: a review. J Clin Microbiol 36(10): 2803-2809.

18. de Carvalho Costa, Cardinali I, Rocha GA, Rocha AM, de Moura SB, et al. (2003) Evaluation of [13C] urea breath test and Helicobacter pylori stool antigen test for diagnosis of $H$. pylori infection in children from a developing country. J CIin Microbiol 41(7): 3334-3335.

19. Lopes AI, Vale FF, Oleastro M (2014) Helicobacter pylori infectionrecent developments in diagnosis. World J Gastroenterol 20(28): 9299-9313.

20. Elwyn G, Taubert M, Davies S, Brown G, Allison M, et al. (2007) Which test is best for Helicobacter pylori? A cost effectiveness model using decision analysis. Br J Gen Pract 57(538): 401-403.

21. Yosry A, Fouad R, Khairy M (2014) Comparison of efficacy, side effects and treatment response of different first Line Helicobacter pylori eradication regimens based on antibiotic culture and sensitivity. Int J Microbiol lmmunol Res 2(2): 24-32.

22. Megraud F (2012) The challenge of Helicobacter pylori resistance to antibiotics: the comeback of bismuth-based quadruple therapy. Therap Adv Gastroenterol 5(2): 103-109.

23. Rimbara E, Sasatsu M, Graham DY (2013) PCR detection of Helicobacter pylori in clinical samples. Methods Mol Biol 943: 279-287. 
This work is licensed under Creative Commons Attribution 4.0 License

DOI: 10.19080/ARGH.2019.14.555880
Your next submission with JuniperPublishers will reach you the below assets

- Quality Editorial service

- Swift Peer Review

- Reprints availability

- E-prints Service

- Manuscript Podcast for convenient understanding

- Global attainment for your research

- Manuscript accessibility in different formats ( Pdf, E-pub, Full Text, audio)

- Unceasing customer service

Track the below URL for one-step submission https://juniperpublishers.com/online-submission.php 